\title{
Identifying Predictors of Childhood Anaemia in North-East India
}

\author{
Sanku Dey', Sankar Goswami², Tanujit Dey ${ }^{3}$ \\ 'Department of Statistics, St. Anthony's College, Shillong, India; '2Department of Statistics, G.C. College, Silchar, India; \\ ${ }^{3}$ Department of Mathematics, The College of William and Mary, Williamsburg, VA, USA
}

\begin{abstract}
The objective of this study is to examine the factors that influence the occurrence of childhood anaemia in North-East India by exploring dataset of the Reproductive and Child Health-II Survey (RCH-II). The study population consisted of 10,137 children in the age-group of 0-6 year(s) from North-East India to explore the predictors of childhood anaemia by means of different background characteristics, such as place of residence, religion, household standard of living, literacy of mother, total children ever born to a mother, age of mother at marriage. Prevalence of anaemia among children was taken as a polytomous variable. The predicted probabilities of anaemia were established via multinomial logistic regression model. These probabilities provided the degree of assessment of the contribution of predictors in the prevalence of childhood anaemia. The mean haemoglobin concentration in children aged 0-6 year(s) was found to be $11.85 \mathrm{~g} / \mathrm{dL}$, with a standard deviation of $5.61 \mathrm{~g} / \mathrm{dL}$. The multiple logistic regression analysis showed that rural children were at greater risk of severe $(\mathrm{OR}=2.035 ; \mathrm{p}=0.003)$ and moderate $(\mathrm{OR}=1.23 ; \mathrm{p}=0.003)$ anaemia. All types of anaemia (severe, moderate, and mild) were more prevalent among Hindu children $(\mathrm{OR}=2.971 ; \mathrm{p}=0.000)$, $(\mathrm{OR}=1.195 ; \mathrm{p}=0.010)$, and $(\mathrm{OR}=1.201 ; \mathrm{p}=0.011)$ than among children of other religions whereas moderate $(\mathrm{OR}=1.406 ; \mathrm{p}=0.001)$ and mild $(\mathrm{OR}=1.857 ; \mathrm{p}=0.000)$ anaemia were more prevalent among Muslim children. The fecundity of the mother was found to have significant effect on anaemia. Women with multiple children were prone to greater risk of anaemia. The multiple logistic regression analysis also confirmed that children of literate mothers were comparatively at lesser risk of severe anaemia. Mother's age at marriage had a significant effect on anaemia of their children as well.
\end{abstract}

Key words: Anaemia; Multiple logistic regression; Odds ratio; Wald Test statistic; India

\section{INTRODUCTION}

Childhood anaemia is a major public-health concern, with an increasing risk of mortality. Ministry of Health and Family Welfare, Government of India, reports that it is one of the most common diseases due to nutritional deficiency in the world today, and more than half of the population in India is anaemic. The prevalence of anaemia is as high as $70-80 \%$ among children and $60 \%$ among pregnant women (1). Anaemia is a common conundrum of nutritional deficiency worldwide, and its prevalence is higher in developing countries than developed countries $(2,3)$.

Correspondence and reprint requests:

Dr. Sanku Dey

Department of Statistics

St. Anthony's College

Shillong, Meghalaya 793001

India

Email: sanku_dey2k2003@yahoo.com
Almost 34\% of the world population suffers from iron deficiency, with $80 \%$ belonging to developing countries where the prevalence of anaemia and iron deficiency is approximately $40 \%$ whereas, in developed countries, the occurrence of anaemia is lower than $10 \%$ (4). WHO lists iron-deficiency anaemia (IDA) as one of the "top ten risk factors contributing to death" (5). IDA is prevalent in South Asia, predominantly in India, Bangladesh, and Pakistan. However, the prevalence of IDA in Bangladesh and Pakistan has declined to 55\% (6). The waning prevalence of IDA is remarkable in the case of China where the occurrence rate has plummeted from $20 \%$ to $8 \%$ within a decade (7). It is difficult to ascertain the true incidence of IDA as the aetiology of anaemia is multifactorial. A largescale study conducted by Indian Council of Medical Research (ICMR) found that about 53\% of children were anaemic (8). A study by National Family Health Survey-2 (NFHS-2) (9) found the occurrence 
of anaemia among children aged 1-5 year(s) a little lower than adolescents and women of childbearing age, who are at risk of developing anaemia (10). IDA is a public-health crisis in India, especially among pregnant and lactating women, children, and adolescents (11). Over the last 50 years, the prevalence of iron-deficiency anaemia has varied between 68 and $97 \%$ among children $(12,13)$. Different studies in India (14), Indonesia (15), Thailand (16), and the United States (17) have shown that iron-deficiency anaemia leads to psychomotor retardation, low intelligence, and decreased learning capability in children below 5 years and primary school students. The different forms of anaemia also endanger livelihood $(5,18)$.

A number of studies have been conducted on the association between the socioeconomic status (SES) and the prevalence of anaemia (19-21). As SES is a significant determinant of access to healthcare, a large number of people live with no or restricted access to medical attention and preventive measures (22), which results in ever-increasing risk of becoming anaemic.

The factors that influence the occurrence of anaemia in a population are fundamental to the implementation of control measures. Bearing this in mind, our aim was to determine the prevalence of anaemia among children aged 0-6 year(s) from the northeastern states of India and to identify the predictors that are significantly associated with anaemia. To comprehend the prevalence of anaemia, socioeconomic differentials have also been taken into consideration.

\section{MATERIALS AND METHODS}

\section{Data}

The study used data from Reproductive and Child Health-II Survey, 2002-2004 (23) for the northeastern states of India. The RCH-II survey was carried out throughout India in two phases by the Ministry of Health and Family Welfare, Government of India and funded by the World Bank. International Institute for Population Sciences (IIPS), Mumbai, collected the data as a nodal agency with the help of different regional agencies in various districts of the country. The survey used a systematic multistage stratified sampling; the stages of selection were districts, primary sampling units (PSUs), and households; 1,000 representative households were identified for the survey, using appropriate sampling procedure from each district. Thirty percent of the sample was selected from urban areas and was based on National Sample Survey Organisation (NSSO) urban sampling frame. The survey provided district-level information on the prevalence of undernutrition [weight-for-age, using the standard deviation (SD) classification] among children in the age-group of 0-72 month(s); prevalence of anaemia ( $\mathrm{Hb}$ estimation by indirect cyanmethemoglobin method) in children aged 0-72 month(s), adolescent girls aged 10-19 year(s), and pregnant women; household availability of iodized salt; and the coverage of vitamin A programme, with appropriate dosage. Details of the survey are available elsewhere (23). To meet the objectives of the study, we produced a file that pertains to the northeastern states of India. Our study comprises 10,137 children within 0-6 year(s) of age.

Levels of anaemia were classified as severe, moderate, and mild, based on the haemoglobin concentrations and according to the specification of the World Health Organization (24). Severe anaemia was diagnosed as haemoglobin concentration less than $7.0 \mathrm{~g} / \mathrm{dL}$, moderate anaemia as haemoglobin concentration 7.0-9.9 g/dL, and mild anaemia as haemoglobin concentration 10.0-10.9 g/dL.

\section{Method of analysis}

In this study, a predictive model on childhood anaemia was developed by using multinomial logistic regression technique. To assess the degree of association between the risk factors and anaemia, odds ratios were computed. The data on predictors were based on: place of residence, standard of living, sex of the child, literacy of mother, total number of children ever born to a mother, and age of the mother at marriage. The response variable was designed as polytomous anaemia level Y ( $1=$ severely anaemic, $2=$ moderately anaemic, $3=$ mildly anaemic, and $4=$ non-anaemic).

Wald Test statistic was used in testing the significance of the logistic regression coefficients. SPSS (version 11.0) was used for analyzing the data, and the last category of each predictor was taken as the reference group.

The multinomial logistic regression model is an extension of the binary logistic regression model where the dependent variable is polytomous, i.e. its values consist of more than two categories. In such cases, if we assume that the possible numbers of categories are q, then we need q-1 logits. The logit multinomial model can be written as:

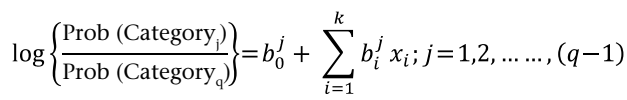


where $b_{0}^{j}=$ intercept for the $\mathrm{j}$-th logit, $b_{i}^{j}=$ regression coefficient for $i$-th predictor $x_{i}$ in the $j$-th logit, $k=$ number of predictors in the model.

In the above expression, one of the categories is used as reference and is called the baseline category. In our study, the different categories are the different levels of anaemia. As a result, we consider nonanaemic as the reference category. After estimating the coefficients of the model (Equation 1) via the method of maximum likelihood, we were able to compute the logits and, hence, the probabilities of each of the categories. The equations for the multiple logistic regressions are:

$\log \left\{\frac{P_{1}}{P_{4}}\right\}=b_{0}^{1}+\sum_{i=1}^{7} b_{i}^{1} x_{i}$

$\log \left\{\frac{P_{2}}{P_{4}}\right\}=b_{0}^{2}+\sum_{i=1}^{7} b_{i}^{2} x_{i}$

$\log \left\{\frac{P_{3}}{P_{4}}\right\}=b_{0}^{3}+\sum_{i=1}^{7} b_{i}^{3} x_{i}$

where $P_{1}=$ Probability of getting severely anaemic, $P_{2}=$ Probability of getting moderately anaemic, $P_{3}=$ Probability of getting mildly anaemic, $P_{4}=$ Probability of getiing non-anaemic, and $P_{1}+P_{2}+P_{3}=1 ;\left\{x_{\mathrm{i}}\right\}^{\prime} \mathrm{s}(i=1,2, \ldots, 7)$ are the aforesaid predictors.; $b_{0}^{1}, b_{0}^{2}$ and, $b_{0}^{3}$ are the regression coefficients of Equation 2 to 4 . Table 1 through 3 represent an overview of the predictors used in the model as well as the sociodemographic temperament of the population.

\section{RESULTS}

In this study, the mean haemoglobin concentration of children of age-group 0-6 year(s) in North-East India was found to be $11.85 \mathrm{~g} / \mathrm{dL}$, with a standard deviation of $5.61 \mathrm{~g} / \mathrm{dL}$. Sociodemographic characteristics of anaemic and non-anaemic groups are presented in Table 3. The data show that, out of 10,137 children in North-East India, 52.5\% were anaemic (1.9\% severely anaemic, $24.7 \%$ moderately anaemic, and $25.9 \%$ mildly anaemic). Table 2 shows that the highest proportion of anaemic children were found in Tripura (74.2\%), followed by Sikkim (69.9\%) and Assam (61.8\%). It was also observed that the prevalence of anaemia was $53.1 \%$ and $51.9 \%$ among male and female children respectively.

The study reveals that rural children were at greater risk of severe $(\mathrm{OR}=2.035 ; \mathrm{p}=0.003)$ and moderate $(\mathrm{OR}=1.230 ; \mathrm{p}=0.003)$ anaemia compared to urban children (Table 4.1 and 4.2). Data show that male children were at greater risk of having severe anaemia than female children (O.R=1.488; $\mathrm{p}=0.010)$ (Table 4.1). Our analysis suggests that children born to literate women were more likely to have moderate

Table 1. Description of predictors in the logistic regression model

\begin{tabular}{|c|c|c|}
\hline Predictor & Name of variable and value level & Type of variable \\
\hline $\mathrm{X} 1$ & $\begin{array}{l}\text { Place of residence } \\
1=\text { Rural, } 2=\text { Urban }\end{array}$ & $\begin{array}{l}\text { Nominal } \\
\text { Categorical }\end{array}$ \\
\hline $\mathrm{X} 2$ & $\begin{array}{l}\text { Religion } \\
\text { 1=Hindu, 2=Muslim } \\
\text { 3=Christian, 4=Others }\end{array}$ & $\begin{array}{l}\text { Nominal } \\
\text { Categorical }\end{array}$ \\
\hline $\mathrm{X} 3$ & $\begin{array}{l}\text { Household standard of living } \\
\text { 1=Low, } 2=\text { Medium, } 3=\text { High }\end{array}$ & $\begin{array}{l}\text { Ordinal } \\
\text { Categorical }\end{array}$ \\
\hline $\mathrm{X} 4$ & $\begin{array}{l}\text { Sex of the child } \\
1=\text { Male, } 2=\text { Female }\end{array}$ & $\begin{array}{l}\text { Nominal } \\
\text { Categorical }\end{array}$ \\
\hline $\mathrm{X} 5$ & $\begin{array}{l}\text { Literacy of mother } \\
\text { 1=Can read and write } \\
\text { 2=Can't read and write }\end{array}$ & $\begin{array}{l}\text { Ordinal } \\
\text { Categorical }\end{array}$ \\
\hline X6 & $\begin{array}{l}\text { Total no. of children ever born to a } \\
\text { mother } 1=\text { Up to two, } 2=\text { Three or four } \\
3=\text { Five or above }\end{array}$ & $\begin{array}{l}\text { Nominal } \\
\text { Categorical }\end{array}$ \\
\hline $\mathrm{X} 7$ & $\begin{array}{l}\text { Age of mother at marriage } \\
1=\text { Below } 18 \text { years, } 2=18-26 \text { years } \\
3=\text { Above } 26 \text { years }\end{array}$ & $\begin{array}{l}\text { Nominal } \\
\text { Categorical }\end{array}$ \\
\hline
\end{tabular}




\begin{tabular}{|c|c|c|c|c|c|}
\hline \multirow[b]{2}{*}{ State } & \multicolumn{4}{|c|}{ Anaemia level } & \multirow[b]{2}{*}{ Total } \\
\hline & $\begin{array}{l}\text { Severely } \\
\text { anaemic }\end{array}$ & $\begin{array}{l}\text { Moderately } \\
\text { anaemic }\end{array}$ & $\begin{array}{c}\text { Mildly } \\
\text { anaemic }\end{array}$ & Non-anaemic & \\
\hline Sikkim & $\begin{array}{c}29 \\
4.1 \%\end{array}$ & $\begin{array}{c}283 \\
40.0 \%\end{array}$ & $\begin{array}{c}190 \\
26.8 \%\end{array}$ & $\begin{array}{c}206 \\
29.1 \%\end{array}$ & $\begin{array}{c}708 \\
100.0 \%\end{array}$ \\
\hline $\begin{array}{l}\text { Arunachal } \\
\text { Pradesh }\end{array}$ & $\begin{array}{c}24 \\
0.8 \%\end{array}$ & $\begin{array}{c}639 \\
21.9 \%\end{array}$ & $\begin{array}{c}639 \\
21.9 \%\end{array}$ & $\begin{array}{c}1,611 \\
55.3 \%\end{array}$ & $\begin{array}{c}2,913 \\
100.0 \%\end{array}$ \\
\hline Nagaland & $\begin{array}{c}6 \\
1.1 \%\end{array}$ & $\begin{array}{c}82 \\
15.6 \%\end{array}$ & $\begin{array}{c}160 \\
30.4 \%\end{array}$ & $\begin{array}{c}278 \\
52.9 \%\end{array}$ & $\begin{array}{c}526 \\
100.0 \%\end{array}$ \\
\hline Manipur & $\begin{array}{c}17 \\
0.8 \%\end{array}$ & $\begin{array}{c}457 \\
21.9 \%\end{array}$ & $\begin{array}{c}411 \\
19.7 \%\end{array}$ & $\begin{array}{c}1198 \\
57.5 \%\end{array}$ & $\begin{array}{c}2,083 \\
100.0 \%\end{array}$ \\
\hline Mizoram & $\begin{array}{c}13 \\
2.0 \%\end{array}$ & $\begin{array}{c}138 \\
20.8 \%\end{array}$ & $\begin{array}{c}215 \\
32.5 \%\end{array}$ & $\begin{array}{c}296 \\
44.7 \%\end{array}$ & $\begin{array}{c}662 \\
100.0 \%\end{array}$ \\
\hline Tripura & $\begin{array}{c}6 \\
1.7 \%\end{array}$ & $\begin{array}{c}156 \\
43.2 \%\end{array}$ & $\begin{array}{c}106 \\
29.4 \%\end{array}$ & $\begin{array}{c}93 \\
25.8 \%\end{array}$ & $\begin{array}{c}361 \\
100.0 \%\end{array}$ \\
\hline Meghalaya & $\begin{array}{c}6 \\
3.0 \%\end{array}$ & $\begin{array}{c}34 \\
17.1 \%\end{array}$ & $\begin{array}{c}54 \\
27.1 \%\end{array}$ & $\begin{array}{c}105 \\
52.8 \%\end{array}$ & $\begin{array}{c}199 \\
100.0 \%\end{array}$ \\
\hline Assam & $\begin{array}{c}94 \\
3.5 \%\end{array}$ & $\begin{array}{c}710 \\
26.4 \%\end{array}$ & $\begin{array}{c}855 \\
31.8 \%\end{array}$ & $\begin{array}{c}1026 \\
38.2 \%\end{array}$ & $\begin{array}{c}2,685 \\
100.0 \%\end{array}$ \\
\hline Total & $\begin{array}{c}195 \\
1.9 \%\end{array}$ & $\begin{array}{l}2,499 \\
24.7 \%\end{array}$ & $\begin{array}{r}2,630 \\
25.9 \%\end{array}$ & $\begin{array}{l}4,813 \\
47.5 \%\end{array}$ & $\begin{array}{l}10,137 \\
100.0 \%\end{array}$ \\
\hline
\end{tabular}

$(\mathrm{OR}=1.126 ; \mathrm{p}=0.036)$ and mild $(\mathrm{OR}=1.047 ; \mathrm{p}=0.412)$ anaemia compared to children born to non-literate women (Table 4.2). Results show that all types of anaemia (severe, moderate, and mild) were more prevalent $(\mathrm{OR}=2.971 ; \mathrm{p}=0.000),(\mathrm{OR}=1.195$; $\mathrm{p}=0.010)$, and $(\mathrm{OR}=1.201 ; \mathrm{p}=0.011)$ among Hindu children than children of other religious groups whereas moderate $(\mathrm{OR}=1.406 ; \mathrm{p}=0.001)$ and mild $(\mathrm{OR}=1.857 ; \mathrm{p}=0.000)$ anaemia were more prevalent among Muslim children (Table 4.1, 4.2, and 4.3). This indicates that, compared to children of other communities, the associated risks of anaemia for Hindu children will increase by 2.971 for severe, 1.195 for moderate, and 1.201 for mild aneamia. The said risks for Muslim children will increase by 1.748 times for severe, 1.406 times for moderate, and 1.857 times for mild anaemia.

The odds ratios and $\mathrm{p}$ values in both severe and moderate groups suggest that children from households with low and medium standard of living were more likely to have anaemia $(\mathrm{OR}=1.306 ; \mathrm{p}=0.381$; $\mathrm{OR}=1.609 ; \mathrm{p}=0.089)$ and $(\mathrm{OR}=1.165 ; \mathrm{p}=0.102$; $\mathrm{OR}=1.164 ; \mathrm{p}=0.103)$ compared to those with high standard of living (Table 4.1 and 4.2).

Mother's fertility also appeared to be closely associated with anaemia in their children. Results show that the risk of anaemia increased with the fertility of mother, i.e. more the number of children ever born to a mother, the more the possibility of the children being anaemic. The odds ratios also reflect that higher the mother's age at marriage, the more the likelihood of the children being mildly anaemic (Table 4.1, 4.2, and 4.3).

Results illustrate that certain factors, namely place of residence, religion, household standard of living, gender of the child, and total number of children ever born to a mother, stimulate anaemia in children (Table 5).

\section{DISCUSSION}

In this study, high prevalence of anaemia was observed among children aged 0-6 year(s) in the northeastern states of India. This trend is widespread not only in India and Brazil but also in other developing countries. In New Zealand, the prevalence of anaemia was found to be $49 \%$ among children aged 6-11 months and 22\% among children aged 12-24 months (25). In Viet Nam, $45.1 \%$ of children below the age of 5 years were found to be suffering from anaemia (26). In sub-Saharan African countries, prevalence of anaemia was recorded to be $82 \%$ in Benin and $83 \%$ in Mali (27). 


\begin{tabular}{|c|c|c|c|c|c|}
\hline Variable & $\begin{array}{l}\text { Severely } \\
\text { anaemic }\end{array}$ & $\begin{array}{l}\text { Moderately } \\
\text { anaemic }\end{array}$ & $\begin{array}{l}\text { Mildly } \\
\text { anaemic }\end{array}$ & Non-anaemic & Total \\
\hline \multicolumn{6}{|l|}{ Place of residence } \\
\hline Urban & $171(2.1 \%)$ & 2,052 (25.4\%) & 2,033(25.2\%) & 3,818 (47.3\%) & $8,074(100 \%)$ \\
\hline Rural & $24(1.2 \%)$ & 447 (21.7\%) & 597 (28.9\%) & $995(48.2 \%)$ & $2,063(100 \%)$ \\
\hline \multicolumn{6}{|l|}{ Religion } \\
\hline Hindu & $116(3.1 \%)$ & 1,024 (27.1\%) & 965 (25.6\%) & 1,667 (44.2\%) & $3,772(100 \%)$ \\
\hline Muslim & $14(1.5 \%)$ & 250 (27.1\%) & 309 (33.5\%) & 350 (37.9\%) & 923 (100\%) \\
\hline Christian & 40 (1.2\%) & 713 (20.5\%) & 894 (25.7\%) & 1,825 (52.6\%) & $3,472(100 \%)$ \\
\hline Others & $25(1.3 \%)$ & $512(26.0 \%)$ & $462(23.5 \%)$ & $971(49.3 \%)$ & $1,970(100 \%)$ \\
\hline \multicolumn{6}{|l|}{$\begin{array}{l}\text { Household standard } \\
\text { of living }\end{array}$} \\
\hline Low & $116(1.9 \%)$ & $1,544(25.1 \%)$ & 1,535 (25.0\%) & $2,956(48.1 \%)$ & $6,151(100 \%)$ \\
\hline Medium & $64(2.2 \%)$ & 695 (24.4\%) & 775 (27.2\%) & 1,312(46.1\%) & $2,846(100 \%)$ \\
\hline High & $15(1.3 \%)$ & $260(22.8 \%)$ & $320(28.1 \%)$ & $545(47.8 \%)$ & $1,140(100 \%)$ \\
\hline \multicolumn{6}{|l|}{ Sex of the child } \\
\hline Male & $117(2.2 \%)$ & 1,294 (24.7\%) & 1,365 (26.1\%) & $2,453(46.9 \%)$ & $5,229(100 \%)$ \\
\hline Female & 78 (1.6\%) & $1,205(24.6 \%)$ & $1,265(25.8 \%)$ & $2,360(48.1 \%)$ & 4,908 (100\%) \\
\hline \multicolumn{6}{|l|}{ Literacy of mother } \\
\hline Can read and write & $105(1.8 \%)$ & $1,464(24.9 \%)$ & $1,532(26.1 \%)$ & $2,772(47.2 \%)$ & $5,873(100 \%)$ \\
\hline Can't read and write & $78(2.0 \%)$ & $959(24.6 \%)$ & $993(25.5 \%)$ & 1,867 (47.9\%) & 3,897 (100\%) \\
\hline \multicolumn{6}{|l|}{$\begin{array}{l}\text { Total no. of children } \\
\text { ever born to a mother }\end{array}$} \\
\hline Up to two & $91(2.1 \%)$ & 1,115 (26.0\%) & 1,062 (24.8\%) & 2,015 (47.0\%) & $4,283(100 \%)$ \\
\hline Three or four & $59(1.6 \%)$ & $885(23.8 \%)$ & $964(26.0 \%)$ & $1,805(48.6 \%)$ & $3,713(100 \%)$ \\
\hline Five or above & $33(1.9 \%)$ & $23(23.8 \%)$ & $499(28.1 \%)$ & $819(46.2 \%)$ & $1,774(100 \%)$ \\
\hline \multicolumn{6}{|l|}{$\begin{array}{l}\text { Age of mother at } \\
\text { marriage }\end{array}$} \\
\hline Below 18 years & $54(1.7 \%)$ & $771(24.6 \%)$ & 758 (24.1\%) & $1,556(49.6 \%)$ & $3,139(100 \%)$ \\
\hline $18-26$ years & $121(2.0 \%)$ & $1,532(25.0 \%)$ & $1,630(26.6 \%)$ & 2,847 (46.4\%) & $6,130(100 \%)$ \\
\hline Above 26 years & $8(1.6 \%)$ & 120 (24.0\%) & 137 (27.3\%) & 236 (47.1\%) & 501 (100\%) \\
\hline
\end{tabular}

According to National Family Health Survey-3 (NFHS-3), 79\% of children aged 6-59 months were anaemic, including $40 \%$ who were moderately anaemic and 3\% who were severely anaemic. The only states where less than half of the children were anaemic are Goa (38\%), Manipur (41\%), Mizoram (44\%), and Kerala (45\%). In contrast to the findings of NFHS-3, our study reveals that, in Arunachal Pradesh (44.7\%), Nagaland (47.1\%), Manipur (42.5\%), and Meghalaya (47.2\%), less than half of the children were anaemic. In conformity to our finding, several other studies (28-31) carried out on childhood anaemia indicated that children living in rural areas were at greater risk of anaemia compared to their urban counterparts. While some studies $(28,32)$ reported that there was no association between gender and anaemia, others as well as our results showed that male children were at greater risk of anaemia than female children $(29,33)$.

Children in households with low and medium standard of living index were more likely to have anaemia compared to their counterparts, which corroborates the findings of studies carried out in Brazil and other countries $(34,35)$. The literacy factor shows that children of literate mothers were comparatively at lesser risk of severe anaemia than children of non-literate mothers but they too were at higher risk of moderate and mild anaemia. This confirms the findings of National Family Health Survey-3 (1), which revealed 


\begin{tabular}{|lcccccccc|}
\hline \multicolumn{7}{l}{ Table 4.1. Parameters of multiple logistic regression model (Group: Severe anaemia) } \\
\hline Predictor & $\hat{\beta}$ & $S E(\hat{\beta})$ & Wald test & df & p value & Odds ratio & \multicolumn{2}{c|}{$95 \%$ CI for OR } \\
\cline { 7 - 9 } & & & & & & & Lower & Upper \\
\hline Intercept & -4.649 & 556 & 69.927 & 1 & 0.000 & - & - & - \\
{$[\mathrm{X} 1=1]$} & 0.710 & 0.239 & 8.860 & 1 & 0.003 & 2.035 & 0.275 & 3.248 \\
{$[\mathrm{X} 1=2]$} & 0 & - & - & 0 & - & - & - & - \\
{$[\mathrm{X} 2=1]$} & 1.089 & 0.233 & 21.914 & 1 & 0.000 & 2.971 & 1.883 & 4.688 \\
{$[\mathrm{X}=2]$} & 0.558 & 0.353 & 2.496 & 1 & 0.114 & 1.748 & 0.874 & 3.494 \\
{$[\mathrm{X} 2=3]$} & $-9.417 \mathrm{E}-02$ & 0.270 & 0.122 & 1 & 0.727 & 0.910 & 0.537 & 1.544 \\
{$[\mathrm{X}=4]$} & 0 & - & - & 0 & - & - & - & - \\
{$[\mathrm{X} 3=1]$} & 0.267 & 0.305 & 0.766 & 1 & 0.381 & 1.306 & 0.718 & 2.377 \\
{$[\mathrm{X} 3=2]$} & 0.512 & 0.312 & 2.897 & 1 & 0.089 & 1.669 & 0.925 & 3.009 \\
{$[\mathrm{X} 3=3]$} & 0 & - & - & 0 & - & - & - & - \\
{$[\mathrm{X} 4=1]$} & 0.398 & 0.155 & 6.596 & 1 & 0.010 & 1.488 & 1.099 & 2.016 \\
{$[\mathrm{X} 4=2]$} & 0 & - & - & 0 & - & - & - & - \\
{$[\mathrm{X} 5=1$} & $-6.661 \mathrm{E}-02$ & 0.169 & 0.154 & 1 & 0.694 & 0.936 & 0.671 & 1.304 \\
{$[\mathrm{X} 5=2]$} & 0 & - & - & 0 & - & - & - & - \\
{$[\mathrm{X} 6=1]$} & -0.101 & 0.222 & 0.209 & 1 & 0.648 & 0.904 & 0.585 & 1.396 \\
{$[\mathrm{X} 6=2]$} & -0.287 & 0.226 & 1.612 & 1 & 0.204 & 0.751 & 0.482 & 1.169 \\
{$[\mathrm{X} 6=3]$} & 0 & - & - & 0 & - & - & - & - \\
{$[\mathrm{X} 7=1]$} & -0.251 & 0.394 & 0.407 & 1 & 0.523 & 0.778 & 0.360 & 1.683 \\
{$[\mathrm{X} 7=2]$} & $5.835 \mathrm{E}-02$ & 0.375 & 0.024 & 1 & 0.876 & 1.060 & 0.509 & 2.209 \\
{$[\mathrm{X} 7=3]$} & 0 & - & - & 0 & - & - & - & - \\
\hline
\end{tabular}

\begin{tabular}{|c|c|c|c|c|c|c|c|c|}
\hline \multirow{2}{*}{ Predictor } & \multirow{2}{*}{$\hat{\beta}$} & \multirow{2}{*}{$S E(\hat{\beta})$} & \multirow{2}{*}{ Wald test } & \multirow{2}{*}{ df } & \multirow{2}{*}{$\mathrm{p}$ value } & \multirow{2}{*}{ Odds ratio } & \multicolumn{2}{|c|}{$95 \%$ CI for OR } \\
\hline & & & & & & & Lower & Upper \\
\hline Intercept & 0.908 & 0.168 & 29.327 & 1 & 0.000 & - & - & - \\
\hline$[\mathrm{X} 1=1]$ & 0.207 & 0.070 & 8.595 & 1 & 0.003 & 1.230 & 1.071 & 1.412 \\
\hline$[\mathrm{X} 1=2]$ & 0 & - & - & 0 & - & - & - & - \\
\hline$[\mathrm{X} 2=1]$ & 0.178 & 0.069 & 6.591 & 1 & 0.010 & 1.195 & 1.043 & 1.369 \\
\hline$[\mathrm{X} 2=2]$ & 0.341 & 0.103 & 10.901 & 1 & 0.001 & 1.406 & 1.148 & 1.721 \\
\hline$[\mathrm{X} 2=3]$ & -0.0339 & 0.074 & 21.126 & 1 & 0.000 & 0.713 & 0.617 & 0.824 \\
\hline$[\mathrm{X} 2=4]$ & 0 & - & - & 0 & - & - & - & - \\
\hline$[\mathrm{X} 3=1]$ & 0.153 & 0.094 & 2.675 & 1 & 0.102 & 1.165 & 0.970 & 1.400 \\
\hline$[\mathrm{X} 3=2]$ & 0.152 & 0.093 & 2.661 & 1 & 0.103 & 1.164 & 0.970 & 1.398 \\
\hline [X3=3] & 0 & - & - & 0 & - & - & - & - \\
\hline$[\mathrm{X} 4=1]$ & $2.952 \mathrm{E}-02$ & 0.050 & 0.342 & 1 & 0.559 & 1.030 & 0.933 & 1.137 \\
\hline$[X 4=2]$ & 0 & - & - & 0 & - & - & - & - \\
\hline$[\mathrm{X} 5=1]$ & 0.119 & 0.057 & 4.383 & 1 & 0.036 & 1.126 & 1.008 & 1.259 \\
\hline$[\mathrm{X} 5=2]$ & 0 & - & - & 0 & - & - & - & - \\
\hline$[\mathrm{X} 6=1]$ & $-1.058 \mathrm{E}-02$ & 0.075 & 0.020 & 1 & 0.888 & 0.989 & 0.854 & 1.146 \\
\hline$[\mathrm{X} 6=2]$ & $-6.968 \mathrm{E}-02$ & 0.074 & 0.883 & 1 & 0.347 & 0.933 & 0.807 & 1.079 \\
\hline$[\mathrm{X} 6=3]$ & 0 & - & - & 0 & - & - & - & - \\
\hline$[\mathrm{X} 7=1]$ & -0.189 & 0.124 & 2.339 & 1 & 0.126 & 0.828 & 0.650 & 1.055 \\
\hline$[\mathrm{X} 7=2]$ & $-3.293 \mathrm{E}-02$ & 0.118 & 0.078 & 1 & 0.780 & 0.968 & 0.768 & 1.219 \\
\hline$[\mathrm{X} 7=3]$ & 0 & - & - & 0 & - & - & - & - \\
\hline
\end{tabular}




\begin{tabular}{|lcccccccc|}
\hline \multicolumn{7}{|l}{ Table 4.3. Parameters of multiple logistic regression model (Group: Mild anaemia) } \\
\hline Predictor & $\hat{\beta}$ & $S E(\hat{\beta})$ & Wald test & df & p value & Odds ratio & \multicolumn{2}{c|}{$95 \%$ CI for OR } \\
\cline { 7 - 9 } & & & & & & Lower & Upper \\
\hline Intercept & 0.386 & 0.161 & 5.774 & 1 & 0.016 & - & - & - \\
{$[\mathrm{X} 1=1]$} & $-7.202 \mathrm{E}-02$ & 0.066 & 1.188 & 1 & 0.276 & 0.931 & 0.817 & 1.059 \\
{$[\mathrm{X} 1=2]$} & 0 & - & - & 0 & - & - & - & - \\
{$[\mathrm{X} 2=1]$} & 0.183 & 0.072 & 6.529 & 1 & 0.011 & 1.201 & 1.043 & 1.381 \\
{$[\mathrm{X} 2=2]$} & 0.619 & 0.101 & 37.709 & 1 & 0.000 & 1.857 & 1.524 & 2.262 \\
{$[\mathrm{X} 2=3]$} & $-2.036 \mathrm{E}-02$ & 0.073 & 0.078 & 1 & 0.781 & 0.980 & 0.849 & 1.131 \\
{$[\mathrm{X} 2=4]$} & 0 & - & - & 0 & - & - & - & - \\
{$[\mathrm{X} 3=1]$} & $-5.994 \mathrm{E}-02$ & -0.090 & 0.448 & 1 & 0.503 & 0.942 & 0.790 & 1.122 \\
{$[\mathrm{X} 3=2]$} & $7.208 \mathrm{E}-02$ & 0.088 & 0.670 & 1 & 0.413 & 1.075 & 0.904 & 1.277 \\
{$[\mathrm{X} 3=3]$} & 0 & - & - & 0 & - & - & - & - \\
{$[\mathrm{X} 4=1]$} & $3.380 \mathrm{E}-02$ & 0.050 & 0.435 & 1 & 0.510 & 1.033 & 0.937 & 1.139 \\
{$[\mathrm{X} 4=2]$} & 0 & - & - & - & - & - & - & - \\
{$[\mathrm{X} 5=1]$} & $4.623 \mathrm{E}-02$ & 0.056 & 0.674 & 1 & 0.412 & 1.047 & 0.938 & 1.170 \\
{$[\mathrm{X} 5=2]$} & 0 & - & - & 0 & - & - & - & - \\
{$[\mathrm{X} 6=1]$} & -0.232 & 0.073 & 10.154 & 1 & 0.001 & 0.793 & 0.688 & 0.915 \\
{$[\mathrm{X} 6=2]$} & -0.160 & 0.071 & 5.095 & 1 & 0.024 & 0.852 & 0.741 & 0.979 \\
{$[\mathrm{X} 6=3]$} & 0 & - & - & 0 & - & - & - & - \\
{$[\mathrm{X} 7=1]$} & -0.306 & 0.119 & 6.594 & 1 & 0.010 & 0.736 & 0.583 & 0.930 \\
{$[\mathrm{X} 7=2]$} & $-7.728 \mathrm{E}-02$ & 0.113 & 0.470 & 1 & 0.493 & 0.926 & 0.742 & 1.154 \\
{$[\mathrm{X} 7=3]$} & 0 & - & - & 0 & - & - & - & - \\
\hline
\end{tabular}

\begin{tabular}{|c|c|c|c|c|}
\hline Effect & $\begin{array}{l}-2 \text { Log likelihood } \\
\text { of reduced model }\end{array}$ & Chi-square & $\mathrm{df}$ & Significance \\
\hline Intercept & 4169.141 & 0.000 & 0 & - \\
\hline X1 & 4192.333 & 23.192 & 3 & 0.000 \\
\hline $\mathrm{X} 2$ & 4322.554 & 153.413 & 9 & 0.000 \\
\hline X3 & 4180.928 & 11.787 & 6 & 0.067 \\
\hline $\mathrm{X} 4$ & 4176.027 & 6.887 & 3 & 0.076 \\
\hline $\mathrm{X} 5$ & 4173.977 & 4.836 & 3 & 0.184 \\
\hline X6 & 4183.501 & 14.361 & 6 & 0.026 \\
\hline X7 & 4191.094 & 21.953 & 6 & 0.001 \\
\hline
\end{tabular}

that more than half of the children were anaemic even when their mothers had 12 or more years of schooling or were in the highest wealth quintile. The fertility of mother was found to have significant effect on anaemia. Multiple children in the family increased the risk of anaemia enormously. Greater the number of children in the household, the greater the needs of the family in terms of domestic work, care of the children, and demand for food, which might possibly heighten the risk of anaemia $(36,37)$. Mother's age at marriage had a considerable effect on anaemia in their children. Children of women who got married between 18 and 26 years were at greater risk of anaemia $(33,38)$. The outcome of our study suggests that socioeconomic factors also influence childhood anaemia. In our study, we have used haemoglobin concentration as a proxy indicator of iron deficiency. Other indicators, such as serum ferritin (39), have not been delved into. Dietary intake, an important determinant of iron deficiency, together with worm infestations, malaria, and the role of infectious diseases, have also been excluded from the study. 


\section{Conclusions}

This paper evaluated the existing endemicity of childhood anaemia in northeastern states of India and summarized the available information to present the extent of occurrence of anaemia among children aged 0-6 year(s). The results suggest that the place of residence, religion, gender of the child, household standard of living, and total number of children ever born to a mother impacted the risk of anaemia in the target population. The available data on the prevalence of anaemia among children of diverse population groups clearly demonstrate that the extent of the problem is astronomical, and the success in combating childhood anaemia depends on comprehending its associated factors. As a result, the implication of the problem necessitates additional comprehensive strategy for sustainable long-term approaches, along with short-term measures for immediate prevention and control of anaemia.

Our study recommends that the high prevalence of mild and moderate anaemia demands due emphasis so as to tackle the overall prevalence of anaemia among children aged 0-6 year(s). Children should be periodically screened, and appropriate measures should be taken for detection and preclusion.

Active collaboration among the government, donor agencies, local academic institutions, nongovernmental organizations, and local communities is idyllic and urgently desired.

\section{ACINOWLEDGEMENTS}

The authors wish to thank the reviewers for their constructive suggestions which led to improvement in the presentation of the paper.

\section{REFERENCES}

1. International Institute for Population Sciences. National Family Health Survey (NFHS-3) 2005-06: India. V. I. Mumbai: International Institute for Population Sciences, 2007. 540 p.

2. Djokic D, Drakulovic MB, Radojicic Z, Crncevic Radovic L, Rakic L, Kocic S et al. Risk factors associated with anaemia among Serbian school-age children 714 years old: results of the first national health survey. Hippokratia 2010;14:252-60.

3. Hioui ME, Farsi M, Aboussaleh Y, Ahami AOT, Achicha A. Prevalence of malnutrition and anaemia among preschool children in Kenitra, Morocco. Nutr Ther Metab 2010;28:73-6.

4. Boccio JR, Iyengar V. Iron deficiency: causes, conse- quences, and strategies to overcome this nutritional problem. Biol Trace Elem Res 2003;94:1-32.

5. Dubey AP. Iron deficiency anaemia: epidemiology, diagnosis and clinical profile. In: Sachdev HPS, Choudhury P, editors. Nutrition in children: developing country concerns. New Delhi: Cambridge Press, 1994:492-24.

6. Gillespie SR, editor. Malnutrition in South Asia: a regional profile. Kathmandu: United Nations Children's Fund, 1997. 189 p. (ROSA publication no. 5).

7. Lokeshwar MR, Manglani M, Rao S, Patel S, Kulkarni $\mathrm{M}$. Iron deficiency-linical manifestation and management. In: Mehta MN, Kulkarni M, editors. Proceedings of national symposium cum work shop on child nutrition: the Indian scene. Bombay: Division of Gastroenterology and Nutrition, LTM Medical College and Hospital, 1990:269-75.

8. Indian Council of Medical Research. Studies on preschool children: report of the working party of the Indian Council of Medical Research. New Delhi: Indian Council of Medical Research, 1974. 58 p. (ICMR technical report series no. 26).

9. Centre for Operations Research and Training. National Family Health Survey, 1998-99 (NFHS-2): Maharashtra. Preliminary report. Vadodara: Centre for Operations Research and Training, 2000. 39 p.

10. Sheeshadri S. Prevalence and implication of nutritional anaemia in children. In: Mehta MN, Kulkarni M, editors. Proceedings of national symposium cum workshop on child nutrition: the Indian scene. Bombay: Division of Gastroenterology and Nutrition, LTM Medical College and Hospital, 1990:22368.

11. Lokeshwar MR, Mehta M, Mehta N, Shelke P, Babar N. Prevention of iron deficiency anaemia (IDA): how far have we reached? Indian J Pediatr 2011;78:593602.

12. Gupte S. Child psychiatry. In: Gupte S, editor. The text book of pediatrics. 9th ed. New Delhi: Jaypee Brothers Medical Publishers, 2004:402.

13. Currimbhor ZE. Survey of anaemia in children of Bombay. J Child Health 1963;469-72.

14. Seshadri S, Gopaldas T. Impact of iron supplementation on cognitive functions in preschool and schoolaged children: the Indian experience. Am J Clin Nutr 1989;50(Suppl 3):675-84.

15. Soemantri AG. Preliminary findings on iron supplementation and learning achievement of rural Indonesian children. Am J Clin Nutr 1989;50(Suppl 3):698701.

16. Pollitt E, Hathirat P, Kotchabhakdi NJ, Missell L, Valyasevi A. Iron deficiency and educational achievement in Thailand. Am J Clin Nutr 1989;50(Suppl 3):687-96. 
17. Pollitt E. Effects of a diet deficient in iron on the growth and development of preschool and schoolaged children. Food Nutr Bull 1991;13:110-8.

18. Cohen BJ, Gibor Y. Anaemia and menstrual blood loss. Obstet Gynecol Surv 1980;35:597-618.

19. Calvo EB, Sosa EM. Iron status in non-pregnant women of child-bearing age living at Greater Buenos Aires. Eur J Clin Nutr 1991;45:215-20.

20. Isah HS, Fleming AF, Ujah IA, Ekwempu CC. Anaemia and iron status of pregnant and non-pregnant women in the Guinea Savanna of Nigeria. Ann Trop Med Parasitol 1985;79:485-93.

21. Johnson AA, Latham MC, Roe DA. The prevalence and the etiology of the nutritional anaemias in Guyana. Am J Clin Nutr 1982;35:309-18.

22. Lovell C, Abed FH. Scaling up in health: two decades of learning in Bangladesh. In: Rohde J, Chatterjee M, Morley D, editors. Reaching health for all. Delhi: Oxford University Press, 1988:212-32.

23. India. Ministry of Health and Family Welfare. State Program Implementation Plans (PIP). New Delhi: Ministry of Health and Family Welfare, Government of India. (http://nrhm.gov.in/nrhm-in-state/stateprogram-implementation-plans-pips.html, accessed on 16 November 2013).

24. DeMaeyer EM. Preventing and controlling iron deficiency anaemia through primary health care: a guide for health administrators and programme managers. Geneva: World Health Organization,1989. 58 p.

25. Soh P, Ferguson EL, McKenzie JE, Homs MYV, Gibson RS. Iron deficiency and risk factors for lower iron stores in 6-24-month-old New Zealanders. Eur J Clin Nutr 2004;58:71-9.

26. Nguyen PH, Nguyen KC, Le Mai B, Nguyen TV, Ha KH, Bern C et al. Risk factors for anaemia in Vietnam. Southeast Asian J Trop Med Public Health 2006;37:1213-23.

27. Ngnie-Teta I, Receveur O, Kuate-Defo B. Risk factors for moderate to severe anaemia among children in Benin and Mali: insights from a multilevel analysis. Food Nutr Bull 2007;28:76-89.

28. Osório MM, Lira PI, Batista-Filho M, Ashworth A. Prevalence of anaemia in children 6-59 months old in the state of Pernambuco, Brazil. Rev Panam Salud Publica 2001;10:101-7.

29. le Cessie S, Verhoeff FH, Mengistie G, Kazembe P, Broadhead R, Brabin BJ. Changes in haemoglobin levels in infants in Malawi: effect of low birth weight and fetal anaemia. Arch Dis Child Fetal Neonatal Ed 2002;86:F182-7.

30. Morasso Mdel C, Molero J, Vinocur P, Acosta L, Paccussi N, Raselli $\mathrm{S}$ et al. [Iron and vitamin A deficiencies and prevalence of anaemia in boys and girls between 6 to 24 months of age in Chaco, Argentina]. Arch Latinoam Nutr 2003;53:21-7. [Spanish].

31. Spinelli MG, Marchioni DM, Souza JM, Souza SB, Szarfarc SC. [Risk factors for anaemia among 6- to 12month-old children in Brazil]. Rev Panam Salud Publica 2005;17:84-91. [Portuguese].

32. Sayyari AA, Sheikhol-Eslam R, Abdollahi Z. Prevalence of anaemia in 2-12-year-old Iranian children. East Mediterr Health J 2006;12:804-8.

33. Unsal A, Bor O, Tozun M, Dinleyici EC, Erenturk G. Prevalence of and related risk factors among 4011 months age infants in Eskischir, Turkey. J Med Sci 2007;7:1335-9.

34. Assunção MCF, da Silva dos Santos I, de Barros AJD, Gigante DP, Victora CG. [Anaemia in children under six: population-based study in Pelotas, Southern Brazil]. Rev Saude Publica 2007;41:328-35. [Portuguese].

35. Mamiro PS, Kolsteren P, Roberfroid D, Tatala S, Opsomer AS, Van Camp JH. Feeding practices and factors contributing to wasting, stunting, and iron-deficiency anaemia among 3-23-month old children in Kilosa district, rural Tanzania. J Health Popul Nutr 2005;23:222-30.

36. Konstantyner T, Taddei JAAC, Oliveira MN, Palma D, Colugnati FAB. Isolated and combined risks for anaemia in children attending the nurseries of daycare centers. J Pediatr (Rio J) 2009;85:209-16.

37. Tympa-Psirropoulou E, Vagenas C, Dafni O, Matala A, Skopouli F. Environmental risk factors for iron deficiency anaemia in children 12-24 months old in the area of Thessalia in Greece. Hippokratia 2008;12:240-50.

38. Agho KE, Dibley MJ, D’Este C, Gibberd R. Factors associated with haemoglobin concentration among Timor-Leste children aged 6-59 months. J Health Popul Nutr 2008;26:200-9.

39. Sinha N, Deshmukh PR, Garg BS. Epidemiological correlates of nutritional anaemia among children (6-35 months) in rural Wardha, Central India. Indian J Med Sci 2008;62:45-54. 